\title{
Optimal management of infrainguinal arterial occlusive disease
}

\author{
This article was published in the following Dove Press journal: \\ Vascular Health and Risk Management \\ 24 October 2014 \\ Number of times this article has been viewed
}

\section{David J Pennywell \\ Tze-Woei Tan \\ Wayne W Zhang}

Division of Vascular and Endovascular Surgery, Louisiana State University Health Shreveport, Shreveport, LA, USA
Correspondence:Tze-Woei Tan

Division of Vascular and Endovascular

Surgery, Louisiana State University Health

Shreveport, I50I Kings Highway, P O Box

33932, Shreveport,

LA 7II 30-3932, USA

$\mathrm{Tel}+13186756154$

Fax + I 3186754689

Email ttan I@Isuhsc.edu
Abstract: Peripheral arterial occlusive disease is becoming a major health problem in Western societies as the population continues to age. In addition to risk of limb loss, the complexity of the disease is magnified by its intimate association with medical comorbidity, especially cardiovascular and cerebrovascular disease. Risk factor modification and antiplatelet therapy are essential to improve long-term survival. Surgical intervention is indicated for intermittent claudication when a patient's quality of life remains unacceptable after a trial of conservative therapy. Open reconstruction and endovascular revascularization are cornerstone for limb salvage in patients with critical limb ischemia. Recent advances in catheter-based technology have made endovascular intervention the preferred treatment approach for infrainguinal disease in many cases. Nevertheless, lower extremity bypass remains an important treatment strategy, especially for reasonable risk patients with a suitable bypass conduit. In this review, we present a summary of current knowledge about peripheral arterial disease followed by a review of current, evidencebased medical and surgical therapy for infrainguinal arterial occlusive disease.

Keywords: peripheral vascular disease, peripheral arterial disease, critical limb ischemia, claudication, infrainguinal bypass, endovascular infrainguinal intervention

\section{Introduction}

Lower extremity arterial occlusive disease is one of the most challenging problems facing vascular specialists, not only because of the complexity of the disease in the legs, but also because of the associated medical comorbidity of patients afflicted with this disease. About 8.5 million people in the US are affected by peripheral arterial disease (PAD), including $4.3 \%$ of adults older than 40 and $14.5 \%$ of those older than $70 .{ }^{1-3}$ Up to $60 \%$ of patients with PAD have associated coronary artery disease (CAD) or cerebrovascular disease ${ }^{4}$ and are at risk of myocardial infarct (MI), stroke, and cardiovascular death. ${ }^{5}$

The most commonly used, objective definition of PAD is a resting ankle-brachial index (ABI) lower than 0.90., ${ }^{2,6}$ Patients with PAD may be asymptomatic, or they may present with intermittent claudication (IC) or chronic critical limb ischemia (CLI). The management of patients with PAD is complex and includes modification of risk factors, pharmacological therapy, supervised exercise therapy, and surgery. Conservative management with analgesia and primary amputation might be appropriate in some patients. ${ }^{2}$

Infrainguinal arterial occlusive disease has been extensively studied, and new tools and techniques for treating it are continually being developed. In this review, we present a summary of current knowledge about the epidemiology, natural history, and clinical 
progression of lower extremity arterial disease followed by a concise, comprehensive synopsis of current, evidence-based medical and surgical therapy.

\section{Risk factors}

Age is the most important, nonmodifiable risk factor for PAD, with a prevalence of $0.9 \%$ in people under age 50 and $23.2 \%$ in people over the age of $80 .{ }^{1}$ Ethnicity and sex are also important factors, with the highest prevalence of PAD seen in African American men and women (prevalence 19.2\%) and Hispanic women (prevalence 19.3\%). ${ }^{1,2}$ The overall prevalence of PAD is greater in men than women. ${ }^{2}$

Several important modifiable risk factors have also been identified..$^{2,7}$ The association between smoking and PAD is well known, and the risk is proportional to the number of cigarettes smoked, with heavy smokers sustaining a four fold risk of developing IC compared to nonsmokers. ${ }^{5,8}$

PAD is about twice as common in diabetic patients as it is in nondiabetics. Furthermore, for every $1 \%$ increase in hemoglobin- $\mathrm{A}_{1 \mathrm{c}}$, there is a $28 \%$ increased risk of developing PAD. ${ }^{9}$

Hypertension is associated with all forms of cardiovascular disease but is not as strong a risk factor for PAD as smoking and diabetes. ${ }^{2}$ Among those who have asymptomatic PAD, hypertension increases the likelihood that they will develop symptoms. The increased risk is 2.5 -fold in men and 3.9-fold in women. ${ }^{9,10}$

Numerous elements of dyslipidemia have been examined and found to have an association with PAD and IC. ${ }^{2,7}$ These include total cholesterol level greater than $270 \mathrm{mg} / \mathrm{dL}$, elevated ratio of total cholesterol to high-density lipoprotein (HDL), low HDL levels, and hypertriglyceridemia. ${ }^{2}$ Smoking magnifies the contribution of dyslipidemia in PAD. ${ }^{2}$

Patients with renal insufficiency, especially postmenopausal women with a history of CAD, are more likely to develop PAD than other patients with a history of CAD who have normal renal function. ${ }^{2,11}$

Hyperhomocysteinemia is a known risk factor for CAD and PAD. Its prevalence among patients with vascular disease is significantly higher than the general population. ${ }^{2,12}$ This is especially true among young patients with $\mathrm{PAD}, 30 \%$ of whom have elevated homocysteine level. ${ }^{12}$

Less intuitive but intriguing is the association of C-reactive protein (CRP) with PAD. ${ }^{2,7,12}$ Recent studies have shown that asymptomatic patients with an elevated CRP are more likely to develop symptomatic PAD over a 5 -year period than age-matched controls in whom CRP is not elevated. ${ }^{2}$ Even among patients with a normal CRP level, those with a level in the top quartile of the normal range are more than twice as likely to develop PAD as those whose CRP level is in the bottom quartile of the normal range. ${ }^{12}$

\section{Natural history}

Patients with asymptomatic PAD and those with IC have a significantly different course than patients with CLI. PAD that is asymptomatic often remains so indefinitely. ${ }^{2}$ Symptoms of IC may worsen over time, but progression to rest pain or tissue loss is unusual. ${ }^{2}$ Factors that increase the likelihood of progression are those listed above, especially smoking and diabetes. ${ }^{2}$ Lower ABI at the time of diagnosis also increases likelihood of progression. Interestingly and importantly, patients with asymptomatic PAD and those with IC share the same increased risk of MI, stroke, and death. ${ }^{2,7}$ This increased risk of fatal cardiovascular and cerebrovascular events is profound compared to the risk of progression to limb-threatening ischemia, with mortality rates as high as $42 \%$ and $65 \%$ at 5 and 10 years, respectively (compared to a 5 -year amputation rate of $<5 \%$ ). ${ }^{13}$

The natural history of CLI is dismal compared to asymptomatic PAD and IC, both in terms of limb survival and overall patient survival. ${ }^{2}$ Mortality for these patients is mostly due to cardiac and cerebrovascular events, and is greater than $25 \%$ at 1 year after diagnosis, ${ }^{13,14}$ greater than $30 \%$ at 2 years, nearly $50 \%$ at 5 years, and $70 \%$ at 10 years., ${ }^{2,14}$ The risk of limb loss is also higher in patients with CLI and is inversely related to $\mathrm{ABI}$. Patients with $\mathrm{CLI}$ and an $\mathrm{ABI}>0.50$ have a $15 \%$ amputation rate at 1 year, whereas those with CLI and an $\mathrm{ABI}<0.50$ have a $34 \%$ amputation rate at 1 year. ${ }^{15}$

\section{Classification of lower extremity arterial disease}

Lower extremity arterial disease has historically been classified into two broad, clinical categories: IC and CLI, based on the distinctly different presentations, natural history, associated morbidity and mortality, and response to treatment characteristic of each. A third category is the population of patients who have an ABI $<0.90$ but are asymptomatic. Within this population are some patients who are truly asymptomatic and others who initially deny symptoms but have significantly shorter walking distances on treadmill testing and report decreased daily activity compared to patients without PAD.

Claudication is fatigue, aching, or burning in a muscle group that is caused by transient ischemia, exacerbated by 
exercise, and relieved by rest. Though often confused with diabetic neuropathy and neurogenic claudication, vascular claudication may be distinguished from these entities by both subjective and objective findings. The pain of diabetic neuropathy is often constant, bilateral, and distributed in a "sock and glove" pattern, while the pain of IC is prominent during exercise, unilateral or asymmetric, and localized to a muscle group. The pain of neurogenic claudication is generally positional rather than exertional, and is relieved by sitting or leaning forward while walking. While vascular claudication is typically localized to a muscle group, such as calf muscles or thigh muscles, the pain of neurogenic claudication is often more diffuse, extending from the buttock to the foot.

CLI is characterized by ischemic rest pain that is persistent, recurring, and dependent on opiate analgesia for at least 2 weeks. In order to help distinguish CLI from nonvascular causes of distal limb pain, an ABI of less than 0.40 is also required to establish the diagnosis. ${ }^{2,16}$ In patients with heavily calcified arteries, in whom measurement of $\mathrm{ABI}$ is inaccurate or impossible, an ankle pressure of less than $50 \mathrm{mmHg}$ or a toe pressure of less than $30 \mathrm{mmHg}$ can be used in lieu of ABI to establish the diagnosis. ${ }^{2}$ Alternatively, ischemic ulceration and/or gangrene of the forefoot or toes may be combined with an ABI less than 0.40, an ankle pressure less than $50 \mathrm{mmHg}$, or a toe pressure less than $30 \mathrm{mmHg}$ to establish the diagnosis. ${ }^{2,16-18}$ Patients who meet this standard definition can be subdivided into critical and subcritical groups. Those with rest pain and an ankle pressure greater than $40 \mathrm{mmHg}$ are considered subcritical and have a $27 \%$ chance of limb survival at 1 year. Those with rest pain and either an ankle pressure less than $40 \mathrm{mmHg}$ or tissue loss are considered critical and have a $5 \%$ chance of limb survival at 1 year. ${ }^{16,18}$

The anatomic patterns of arterial occlusive disease can be classified as inflow occlusion, outflow occlusion, or a combination of both. ${ }^{2}$ The infrarenal aorta and iliac system comprise the inflow vessels to the lower extremity. The claudication caused by chronic occlusion of these vessels is usually proximal (ie, thigh or buttock). If extensive bilateral disease is present, male patients may also complain of erectile dysfunction. The arteries of the leg below the inguinal ligament including superficial femoral artery (SFA), deep femoral artery, popliteal artery, and tibial arteries are considered the outflow vessels. ${ }^{2}$

IC is usually caused by single level occlusive disease, and the most commonly affected vessel is the SFA at the level of Hunter's canal. Extensive collateralization via the deep femoral artery usually limits the effects of isolated SFA occlusion to IC. Conversely, CLI is usually caused by occlusive disease at two or more levels, and they are typically sequential and diffuse. ${ }^{19}$ Significant numbers of patients with CLI have occlusions in the popliteal or tibial arteries, and most have associated disease involving inflow or femoral arteries. ${ }^{19}$ Patients with end stage renal disease, diabetes mellitus (DM), and advanced ischemia are more likely to have occlusion in the popliteal and tibial vessels. ${ }^{19}$

\section{Medical therapy Risk factor modification}

Initial treatment of PAD is cardiovascular risk factor modification and antiplatelet therapy to reduce risk of associated cardiovascular and cerebrovascular complications and improve long-term survival., ${ }^{2,7}$ This includes smoking cessation, glycemic control in DM, blood pressure control, statin therapy, and antiplatelet therapy.

While some controversy exists regarding the effect of smoking cessation on regression of symptoms of claudication, the effect of smoking on progression of symptoms, ${ }^{20}$ increased risk of amputation, failure of surgical therapy, and increased risk of death from cardiac and cerebrovascular events is undisputed. ${ }^{2,20}$ All patients with PAD should, therefore, be advised to stop smoking. Face to face counseling, involvement in support groups, and pharmacological therapy in the form of nicotine replacement and bupropion are usually needed.

Diabetes has been shown to increase risk of PAD and cardiac disease, but the effectiveness of tight glycemic control with regard to halting the progression of PAD, relieving symptoms of claudication, or increasing amputation-free survival is unclear. Nevertheless, poorly controlled diabetes should be addressed and corrected. The current recommendation for control of diabetes in PAD is to achieve hemoglobin- $A_{10}$ of $<7 \%$. ${ }^{2,7}$

Hypertension should be treated according to the recommendations of the Eighth Joint National Committee. ${ }^{21}$ Patients older than 65 who do not have DM or chronic kidney disease (CKD) should maintain a systolic blood pressure $<150 \mathrm{mmHg}$ and a diastolic blood pressure $<90 \mathrm{mmHg}$. Patients between the ages of 18 and 65 who do not have DM or CKD and patients of any age who do have DM and/or CKD should maintain a systolic blood pressure $<140 \mathrm{mmHg}$ and a diastolic blood pressure $<90 \mathrm{mmHg}$. The choice of drug depends on race and the presence of CKD. ${ }^{21}$ The notion that reduction of blood pressure in a patient who 
is acclimated to a hypertensive state might worsen symptoms and decrease walking distance has been shown to be inaccurate.

Patients with PAD are considered to have clinical atherosclerotic cardiovascular disease and are, therefore, included in the first of four major statin benefit groups, according to the 2013 American College of Cardiology/American Heart Association (ACC/AHA) guidelines for treatment of blood cholesterol. ${ }^{22}$ These patients benefit from high-intensity statin therapy (atorvastatin 40-80 mg/day or rosuvastatin $20 \mathrm{mg} /$ day). ${ }^{22}$ The expected response to high-intensity statin therapy is a reduction in serum low-density lipoprotein cholesterol by $\geq 50 \%$. If this response is not achieved with high-intensity statin therapy, even in the setting of diligent compliance with lifestyle modification, addition of a nonstatin agent may be considered. ${ }^{22}$

Antiplatelet therapy does not improve symptoms or walking performance in $\mathrm{IC}$; nevertheless, patients with athereosclerotic occlusive disease should be started on long-term antiplatelet therapy in order to reduce the risk of MI, ischemic stroke, and cardiovascular death. ${ }^{2,7}$ A meta-analysis from the Antithrombotic Trialists' Collaboration showed that antiplatelet therapy may reduce the risk of adverse cardiovascular events in patients with PAD by up to $23 \% .{ }^{23}$ The benefits are similar for subgroups of PAD patients with IC, those undergoing open bypass surgery, and those receiving endovascular intervention. ${ }^{23}$ Aspirin was the most widely studied antiplatelet drug and doses of 75-150 mg daily are as effective as higher daily doses. ${ }^{23}$

The Clopidogrel versus Aspirin in Patients at Risk of Ischemic Events trial has found clopidogrel to be more effective than aspirin at further reducing the risk of ischemic stroke, MI, and vascular death in patients with atherosclerotic vascular disease. ${ }^{24}$ The overall safety of clopidogrel is equivalent to medium dose aspirin. There is, however, no benefit in combination therapy of aspirin and clopidogrel in this patient population..$^{2,7}$

\section{Nonsurgical management of intermittent claudication}

Exercise therapy is effective and recommended as initial treatment for patients with IC. ${ }^{2,7}$ Supervised exercise therapy is significantly more effective than nonsupervised therapy. ${ }^{25}$ A meta-analysis of 21 studies of exercise therapy showed that walking distance to onset of claudication increased up to $180 \%$, and walking distance to maximal claudication pain increased up to $122 \%{ }^{26}$ The program is most effective when the duration of each session is greater than 30 minutes, the frequency is more than three sessions per week, and the overall program length is more than 6 months. ${ }^{26}$ There are also some studies that show exercise therapy to be equivalent and at times superior to surgical or endovascular intervention for patients with $\mathrm{IC}^{27}$

Pentoxifylline and cilostazol are the two drugs that have been approved by the US Food and Drug Administration for treatment of claudication. ${ }^{2,7}$ The effectiveness of other agents including L-arginine, propionyl-L-carnitine, ginkgo biloba, oral vasodilator prostaglandins, vitamin $\mathrm{E}$, and chelation is not well established for IC. ${ }^{2,7}$ Cilostazol, a phosphodiesterase III inhibitor, increases walking distance up to $50 \%$ and improves quality of life scores. A trial therapeutic course of cilostazol (100 mg orally twice a day for 3-6 months) should be considered for patients with lifestyle-limiting IC. The side effects of cilostazol include headache and diarrhea, and it should not be prescribed in patients with congestive heart failure due to increased risk of cardiovascular death.

Pentoxifylline, a methylxanthine derivative, is thought to improve oxygen delivery by a rheolytic effect and may also inhibit platelet aggregation. Early trials attributed a $12 \%$ improvement in walking distance to this drug. It may be considered as second-line alternative therapy, especially in patients who are intolerant to cilostazol., ${ }^{2,7}$

\section{Revascularization}

Diagnosis of lower extremity arterial disease must begin with a thorough and comprehensive history, with special attention paid to signs and symptoms of undiagnosed cardiovascular and cerebrovascular disease. ${ }^{2,7}$ Both lower extremities and feet should be thoroughly examined for signs of ischemia. Signs of previous intervention related to vascular disease, such as surgically absent digits and incisions in the groin or legs, may also be noted. Careful assessment of cardiopulmonary reserve and surgical risk is paramount in developing appropriate treatment strategy for these patients. The diagnosis of PAD can be confirmed with $\mathrm{ABI}$ and noninvasive vascular testing. ${ }^{2}$ The distribution and pattern of disease are ascertained using duplex ultrasound, imaging studies such as computed tomographic angiography or magnetic resonance angiography, and catheter-based angiogram. ${ }^{2,7}$ Finally, duplex vein mapping of lower and upper extremities is performed to evaluate for the availability of autogenous conduit for bypass.

Surgical options for management of infrainguinal arterial occlusive disease are conceptually grouped into two major categories: open reconstruction/bypass and endovascular therapy. Multiple factors determine which approach is most beneficial for a given patient, and a comprehensive understanding of the patient's needs and goals for therapy is, therefore, an essential companion to thorough knowledge of the expected 
risk and durability of the surgical options available. The goal of therapy in claudication is improvement in symptoms and quality of life. ${ }^{2}$ For CLI patients, the goal of therapy is pain control, wound healing, and preservation of a functional limb for ambulation. ${ }^{2,17}$

The Transatlantic Inter-Society Consensus (TASC) Working Group classified PAD based on anatomical location (aorto-iliac, femoropopliteal, or infrapopliteal) and severity of the disease (type A, B, C, or D). ${ }^{2}$ Recommendations for an open or endovascular approach are based on the likelihood of therapeutic success. Endovascular therapy is generally preferred for type A/B lesions, whereas open revascularization is recommended for more severe type $\mathrm{C} / \mathrm{D}$ lesions. ${ }^{2}$ For type $\mathrm{B} / \mathrm{C}$ lesions, endovascular and open therapy are both acceptable depending on patient's surgical risk, individual practitioner's preference, and expected durability of the intervention.

Inflow disease involving aortic and iliac levels should always be addressed first with endovascular or open reconstruction prior to or during treatment of infrainguinal occlusive disease. The most important determinant of success in open bypass is the quality of the conduit. For endovascular intervention, the most important determinants of success are the anatomical and morphological characteristic of the lesions. ${ }^{2,17}$ The quality of runoff vessels also correlates with the success of both open and endovascular interventions. For a patient with IC or rest pain, treatment of single level disease, such as an iliac (inflow) vessel or the SFA, might be sufficient for symptomatic relief. A patient with tissue loss (ie, ulcer or gangrene), however, requires in-line flow with either open or endovascular revascularization to establish pulsatile blood flow to the foot for successful wound healing and limb salvage.

\section{Endovascular therapy}

Endovascular treatment of PAD has become increasingly popular and successful as improvements in techniques and devices have resulted in better efficacy and longer patency. It has replaced open revascularization as the most commonly used modality in the treatment of lower extremity PAD. ${ }^{28}$ Likely reasons include the less invasive nature of these newer techniques and the belief that failed endovascular intervention will not negatively affect the outcome of subsequent open surgery. The "endovascular first" approach has, however, been challenged recently, with some studies demonstrating a disadvantageous change in the bypass target and an overall worse outcome following open bypass in patients who experienced failure of an initial endovascular intervention. ${ }^{29-32}$
The complications of lower extremity endovascular intervention are categorized by location into puncture site, intervention site, distal vessel, and systemic complications. ${ }^{33}$ Up to $10 \%$ of patients may experience complications from their intervention that result in open surgery, amputation, and/or death. The most common complications are at the puncture site (bleeding, pseudoaneurysm, arteriovenous fistula) and occur in up to $4 \%$ of patients. Thrombosis and arterial rupture at the intervention site, embolization, and dissection in the distal vessel can also occur. Systemic complications, such as renal failure, MI, and stroke, are reported in $<1 \%$ of patients. $^{33}$

The efficacy of endovascular intervention is affected by both clinical and anatomical factors. Outcomes are worse for patients with DM, end stage renal disease, history of previous vascular intervention, and tissue loss at the time of intervention. ${ }^{2,34,35}$ Likewise, long segment occlusions and heavily calcified lesions predict worse outcomes following endovascular intervention. Success is better with short stenosis up to $10 \mathrm{~cm}$ in length. ${ }^{2}$ While long-term antiplatelet therapy with aspirin or clopidogrel is recommended after infrainguinal intervention unless contraindicated, there is no level I evidence for this practice, and the recommendation is likely extrapolated from data in coronary intervention studies. $^{2}$

To date, there is only one prospective, randomized, controlled trial comparing the outcomes of open versus endovascular interventions for patients with CLI ${ }^{31}$ The Bypass versus Angioplasty in Severe Ischemia of the Leg (BASIL) trial randomized 452 patients from 27 United Kingdom hospitals to bypass-first or balloon angioplasty-first strategy. The participants had severe limb ischemia secondary to infrainguinal disease and were suitable candidates for both approaches. The main outcomes, including overall survival and amputationfree survival, were similar between the two strategies at 2 years after randomization. Interestingly, a survival benefit was noted for patients who randomized to bypass-first in the subset of patients who survived beyond 2 years. ${ }^{31}$ Overall hospital cost and quality of life were similar for both groups. ${ }^{32}$ When the results of the BASIL trial were analyzed by treatment received, patients who received surgical bypass after failed percutaneous transluminal angioplasty (PTA) had significantly worse outcomes compared to patients who initially underwent bypass with an autogenous conduit. When bypass was done with a prosthetic conduit, patients who initially underwent angioplasty appeared to fare better. ${ }^{32}$

There are a number of limitations and criticisms for this trial, including the power of the trial, the selection of study 
population, the lack of lesion standardization, the use of angioplasty as the sole technique in endovascular intervention, and the outcomes examined. ${ }^{17}$ Further clinical trials are required to determine optimal approach for patients with CLI.

\section{Infrainguinal disease}

As previously mentioned, the TASC classification system for PAD is specific for each level of disease. With regard to infrainguinal disease, a single stenosis $\leq 10 \mathrm{~cm}$ in length or a single occlusion $\leq 5 \mathrm{~cm}$ in length are considered type A lesions. A single stenosis between 10 and $15 \mathrm{~cm}$ in length (not involving the below-knee portion of the popliteal artery), a single occlusion between 5 and $15 \mathrm{~cm}$ in length (also not involving the below-knee portion of the popliteal artery), multiple stenoses or occlusions (each $\leq 5 \mathrm{~cm}$ in length), lesions in the absence of continuous tibial vessels, heavily calcified occlusions $\leq 5 \mathrm{~cm}$ in length, and single popliteal stenoses are all considered type B lesions. Multiple stenoses or occlusions totaling $>15 \mathrm{~cm}$, with or without heavy calcifications; lesions with recurrent stenosis; and lesions that still require treatment after two endovascular interventions, are all considered type $\mathrm{C}$ lesions. Chronic, total occlusions of the common femoral artery or SFA measuring $>20 \mathrm{~cm}$, with involvement of the popliteal artery; or chronic, total occlusion of the popliteal artery and proximal trifurcation vessels, are considered type D lesions. ${ }^{2}$

PTA with selective stent placement is the most commonly used technique for femoral popliteal disease. ${ }^{2,7,36}$ Primary stent placement is generally not recommended in the common femoral or popliteal artery. ${ }^{2,7}$ Subintimal angioplasty or other adjunctive techniques, including atherectomy and reentry devices, can be utilized to help with initial recanalization of the occluded vessels. Other newer techniques such as self-expanding stents, stent grafts, cutting balloons, and drug-eluting balloons and stents are increasingly used to enhance the effectiveness of PTA, though data available for these promising new technologies are limited. 27,37,38

Evidence for PTA with selective versus routine stent placement in infrainguinal disease, especially in SFA and proximal popliteal arteries, is controversial. Some studies have shown better patency and lower restenosis rate with routine placement of a bare metal stent ${ }^{39,40}$ while others have reported no significant benefit over selective stent placement. ${ }^{41,42}$ The results of recent meta-analyses have supported the preferred strategy of primary PTA and selective stent placement for femoral popliteal disease. ${ }^{36,43}$

Some investigators have studied the use of stent grafts for treatment of long segment femoropopliteal occlusive disease, and reported similar long-term patency when compared to conventional femoral-popliteal bypass using synthetic conduit. ${ }^{44-46}$ The cost of stent grafts is significantly higher compared to conventional bare metal stents, and there are limited data to recommend their routine use in infrainguinal disease. ${ }^{26}$ Drug-eluting stents and drug-coated balloons are designed to limit the process of intimal hyperplasia in hopes of avoiding in-stent restenosis. A number of trials have shown promising early results for their use in femoral popliteal disease. ${ }^{26,47}$ Nevertheless, data for this evolving technology are limited, and further studies are required to prove long-term, cost-effective benefit in lower extremity arterial disease. ${ }^{26}$

\section{Infrapopliteal disease}

As with infrainguinal PAD, the TASC classification divides infrapopliteal lesions into four classes. ${ }^{2,48}$ Type A lesions are single stenoses $<1 \mathrm{~cm}$ long. Multiple focal stenoses $<1 \mathrm{~cm}$ long or stenoses $<1 \mathrm{~cm}$ involving the trifurcation are considered type B lesions. Stenoses 1 to $4 \mathrm{~cm}$ long, occlusions up to $2 \mathrm{~cm}$ long, or extensive stenoses involving the trifurcation are considered type $\mathrm{C}$ lesions. Occlusions $>2 \mathrm{~cm}$ long or diffuse disease constitute type $\mathrm{D}$ lesions.

Endovascular intervention for infrapopliteal occlusive disease is usually reserved for limb salvage in the setting of CLI and is not recommended for IC. ${ }^{2}$ Infrapopliteal PTA can be performed safely with reported initial technical success of 93\%. ${ }^{48,49}$ An endovascular approach is acceptable for TASC A, $\mathrm{B}$, and $\mathrm{C}$ lesions and has even been performed successfully in TASC C/D lesions, although technical failure was more common with TASC D lesions. ${ }^{48,49}$ As expected, secondary interventions are frequently required, but assisted patency and limb salvage rates are acceptable. ${ }^{48,49}$ Although outcomes are generally similar between the strategies of PTA alone and primary stent placement, routine placement of bare metal stents in infrapopliteal vessels is not recommended. ${ }^{2,7}$ Other techniques, including subintimal angioplasty, arterectomy, and drug-eluting balloons and stents have been used successfully in infrapopliteal occlusive disease, but data for these newer technologies are limited.,27

\section{Open reconstruction}

Infrainguinal lower extremity bypass (LEB) using a goodquality vein is the gold standard for revascularization, especially for patients with CLI. ${ }^{31,50}$ Using the combined data from multiple randomized control trials, ${ }^{31,50,51}$ the Society of Vascular Surgery has summarized the expected outcomes of patients who underwent open revascularization for CLI. ${ }^{51}$ 
The overall reported perioperative mortality rate is $2.7 \%$. The major adverse cardiovascular event rate, including death, MI, and stroke, is reported to be $6.2 \%$. The early LEB graft occlusion rate is around $5 \%$, and the expected amputation rate is $2 \%$. At 1 year, the limb salvage rate is $88 \%$ and amputationfree survival is more than $75 \%$.

Infrainguinal bypass is a major arterial reconstruction using a bypass conduit (whether autogenous or prosthetic) that originates at or below the inguinal ligament. Thus, inflow vessels may include the common, deep, or superficial femoral arteries, and can even include the popliteal or tibial arteries depending on pattern of the occlusive disease. ${ }^{2,52}$ Successful bypass depends on the bypass conduit, the quality of the inflow vessel, and the outflow target vessel. Endarterectomy might be required if the inflow is common femoral artery, proximal SFA, or deep femoral artery. ${ }^{2,52}$ In addition to optimal inflow selection and preparation, proper selection of a distal outflow site is essential for successful bypass. A general principle of all LEB is that the ideal outlet of the bypass conduit should be the most proximal artery that has at least one continuous runoff to the foot, as long as there is adequate length of suitable conduit. ${ }^{2,52}$ The outflow vessel most commonly used is a popliteal artery with tibial or peroneal runoff to the foot. Patients with CLI will usually require the use of a tibial or pedal artery as an outflow target due to the more extensive and diffuse nature of the occlusive disease. , $^{2,19,53}$

The most important determinant of success of an LEB is the type and quality of conduit selected..$^{2,17,52}$ Autogenous vein is superior to synthetic graft as conduit for LEB, ${ }^{2,53-55}$ and the great saphenous vein (GSV) is superior to other autologous alternatives. ${ }^{2,55,56}$ An essential step in preoperative planning is evaluation of the GSV with duplex mapping and identification of alternative vein conduits, if needed. An ideal vein conduit should be soft, compressible, at least $3 \mathrm{~mm}$ in diameter, and should not be calcified or sclerotic. If the ipsilateral GSV is unsuitable or unavailable, the contralateral GSV should be used. If no suitable GSV is available, a small saphenous vein or arm vein can be used for bypass with acceptable patency rates. ${ }^{2,57,58}$ The 5-year patency of femoral to above and below knee popliteal bypass with vein is reported to be $66 \%-76 \%$, depending on the indication for revascularization. ${ }^{2,7}$ In patients with a suitable GSV, femoral-tibial bypass can be performed with excellent long-term patency (74\%-80\% 5-year patency). ${ }^{7}$

If a vein conduit is truly unavailable, several synthetic options including heparin-bonded dacron graft, human umbilical vein, polytetrafluoroethylene (PTFE), and expanded PTFE covalently bonded with heparin can be used for LEB. ${ }^{59-65}$ A prosthetic conduit such as PTFE has acceptable outcomes in the above-knee position with reported 5 -year patency up to $60 \% .^{2,66}$ It is, however, less satisfactory in vessels below the knee, and the reported 5-year patency is $31 \%-65 \%{ }^{2,67}$ Some surgeons have utilized adjunctive procedures including vein cuff patch and arteriovenous fistula in hopes of improving the patency of a prosthetic LEB that incorporates below-knee arteries. ${ }^{2,68-70}$ Others have utilized cryopreserved vein as a bypass conduit, especially in the absence of a suitable autogenous conduit when immediate revascularization is necessary following removal of infected graft. $^{71,72}$

Completion studies such as angiography, duplex ultrasound, and angioscopy are effective in detecting intraoperative technical problems and are used by many surgeons to ensure technical adequacy of their LEBs. ${ }^{52}$ Utilization of completion studies varies widely among vascular surgeons, with some routinely performing a completion study (in addition to continuous waveform Doppler) and others only selectively. ${ }^{73}$ Recent study by our group has shown that completion study did not significantly improve bypass patency at discharge or 1 year for both autogenous and prosthetic LEB, and the strategy of selective use of completion imaging intraoperatively is as effective as those who are using it routinely. ${ }^{74}$

Routine clinical examination and duplex surveillance are important elements of postoperative care to ensure long-term graft patency. ${ }^{2,52}$ Multiple studies have shown the cost-effectiveness of routine surveillance after LEB., ${ }^{2,74,75}$ Duplex ultrasound should be performed in the immediate postoperative period and at regular intervals for at least 2 years after surgery. ${ }^{2}$ If a low graft velocity $(<45 \mathrm{~cm} / \mathrm{s})$, a drop of $>0.15$ in ABI, a focal lesion associated with peak systolic velocity of $>300 \mathrm{~cm} / \mathrm{s}$, or a velocity ratio $>3.5$ on duplex ultrasound is found, ${ }^{2,52}$ angiogram is indicated to identify possible de novo graft stenosis that should be addressed with endovascular angioplasty or open surgical revision. $^{2}$

In addition to the protective effect on cardiovascular and cerebral diseases, antiplatelet therapy, in the form of aspirin or clopidogrel, is beneficial for graft patency and is recommended after LEB. ${ }^{2}$ The beneficial effect of antiplatelet therapy seems to be greater in prosthetic LEB. ${ }^{2,76}$ Anticoagulation with warfarin therapy was shown to be significantly better for autogenous LEB in some studies but can be associated with a higher risk of bleeding., ${ }^{2,76,77}$ The decision for long-term anticoagulation after LEB should be made on an individual basis and might be indicated in 
high-risk patients with poor arterial runoff, suboptimal vein conduit, and those who underwent redo operation.

\section{Primary amputation}

Primary amputation without revascularization might be appropriate in patients with overwhelming foot infection or unbearable symptoms in the setting of disease not amenable to reconstruction. ${ }^{2}$ It should also be considered in patients with significant comorbidities, especially when they are nonambulatory at baseline.

\section{Conclusion}

Management of patients with infrainguinal occlusive disease is challenging, and the complexity of the disease is magnified by its intimate association with medical comorbidity. Treatment of associated risk factors and long-term antiplatelet therapy are paramount in these high-risk populations. Intervention for patients with IC should be reserved for those with severe symptoms after failed conservative management. Early revascularization is indicated in appropriately selected patients for limb salvage in patients with CLI. Endovascular interventions have become the preferred initial approach for treatment of infrainguinal arterial occlusive disease. Open infrainguinal bypass remains the gold standard for revascularization in CLI, especially for patients at appropriate surgical risk and with suitable bypass conduit.

\section{Disclosure}

The authors report no conflicts of interest in this work

\section{References}

1. Selvin E, Erlinger TP. Prevalence of and risk factors for peripheral arterial disease in the United States: results from the National Health and Nutrition Examination Survey, 1999-2000. Circulation. 2004;110(6): 738-743.

2. Norgren L, Hiatt WR, Dormandy JA, Nehler MR, Harris KA, Fowkes FG; TASC II Working Group. Inter-Society Consensus for the Management of Peripheral Arterial Disease (TASC II). J Vasc Surg. 2007;45:Suppl S: S5-S67.

3. Go AS, Mozaffarian D, Roger VL, et al; American Heart Association Statistics Committee and Stroke Statistics Subcommittee. Executive summary: heart disease and stroke statistics - 2014 update: a report from the American Heart Association. Circulation. 2014;129(3):399-410.

4. Bhatt DL, Steg PG, Ohman EM, et al; REACH Registry Investigators. International prevalence, recognition, and treatment of cardiovascular risk factors in outpatients with atherothrombosis. JAMA. 2006;295(2):180-189.

5. Murabito JM, Evans JC, Larson MG, Nieto K, Levy D, Wilson PW; Framingham Study. The ankle-brachial index in the elderly and risk of stroke, coronary disease, and death: the Framingham Study. Arch Intern Med. 2003;163(16):1939-1942.

6. Hirsch AT, Criqui MH, Treat-Jacobson D, et al. Peripheral arterial disease detection, awareness, and treatment in primary care. JAMA. 2001;286(11):1317-1324.
7. Hirsch AT, Haskal ZJ, Hertzer NR, et al; American Association for Vascular Surgery; Society for Vascular Surgery; Society for Cardiovascular Angiography and Interventions; Society for Vascular Medicine and Biology; Society of Interventional Radiology; ACC/ AHA Task Force on Practice Guidelines Writing Committee to Develop Guidelines for the Management of Patients With Peripheral Arterial Disease; American Association of Cardiovascular and Pulmonary Rehabilitation; National Heart, Lung, and Blood Institute; Society for Vascular Nursing; TransAtlantic Inter-Society Consensus; Vascular Disease Foundation. ACC/AHA 2005 Practice Guidelines for the management of patients with peripheral arterial disease (lower extremity, renal, mesenteric, and abdominal aortic): a collaborative report from the American Association for Vascular Surgery/Society for Vascular Surgery, Society for Cardiovascular Angiography and Interventions, Society for Vascular Medicine and Biology, Society of Interventional Radiology, and the ACC/AHA Task Force on Practice Guidelines (Writing Committee to Develop Guidelines for the Management of Patients With Peripheral Arterial Disease): endorsed by the American Association of Cardiovascular and Pulmonary Rehabilitation; National Heart, Lung, and Blood Institute; Society for Vascular Nursing; TransAtlantic Inter-Society Consensus; and Vascular Disease Foundation. Circulation. 2006;113(11):e463-e654.

8. Fowkes GR, Housley E, Riemersa RA, et al. Smoking, lipids, glucose intolerance, and blood pressure as risk factors for peripheral atherosclerosis compared with ischemic heart disease in the Edinburgh Artery Study. Am J Epidemiol. 1992;135(4):331-340.

9. Selvin E, Marinopoulos S, Berkenblit G, et al. Meta-analysis: glycosylated hemoglobin and cardiovascular disease in diabetes mellitus. Ann Intern Med. 2004;141(6):421-431.

10. Murabito JM, D'Agostino RB, Silbershatz H, Wilson WF. Intermittent claudication. A risk profile from The Framingham Heart Study. Circulation. 1997;96(1):44-49.

11. O'Hare AM, Vittinghoff E, Hsia J, Shlipak MG. Renal insufficiency and the risk of lower extremity peripheral arterial disease: results from the Heart and Estrogen/Progestin Replacement Study (HERS). J Am Soc Nephrol. 2004;15(4):1046-1051.

12. Ridker PM, Stampfer MJ, Rifai N. Novel risk factors for systemic atherosclerosis: a comparison of C-reactive protein, fibrinogen, homocysteine, lipoprotein(a), and standard cholesterol screening as predictors of peripheral arterial disease. JAMA. 2001;285(19):2481-2485.

13. Muluk SC, Muluk VS, Kelley ME, et al. Outcome events in patients with claudication: a 15-year study in 2777 patients. J Vasc Surg. 2001; 33(2):251-257; discussion 257-258.

14. Long-term mortality and its predictors in patients with critical limb ischaemia. The ICAI Group (Gruppo di Studio dell'Ischemia Cronica Critica degli Arti Inferiori). The Study Group of Critical Chronic Ischemia of the Lower Extremity. Eur J Vasc Endovasc Surg. 1997;14(2):91-95.

15. Marston WA, Davies SW, Armstrong B, et al. Natural history of limbs with arterial insufficiency and chronic ulceration treated without revascularization. J Vasc Surg. 2006;44(1):108-114.

16. Rutherford RB, Baker JD, Ernst C, et al. Recommended standards for reports dealing with lower extremity ischemia: revised version. $J$ Vasc Surg. 1997;26(3):517-538.

17. Conte MS. Critical appraisal of surgical revascularization for critical limb ischemia. J Vasc Surg. 2013;57(Suppl 2):8S-13S.

18. Wolfe JH, Wyatt MG. Critical and subcritical ischaemia. Eur J Vasc Endovasc Surg. 1997;13(6):578-582.

19. Rueda CA, Nehler MR, Perry DJ, et al. Patterns of artery disease in 450 patients undergoing revascularization for critical limb ischemia: implications for clinical trial design. J Vasc Surg. 2008;47(5):995-999; discussion 999-1000.

20. Hankey GJ, Norman PE, Eikelboom JW. Medical treatment of peripheral arterial disease. JAMA. 2006;295(5):547-553.

21. James PA, Oparil S, Carter BL, et al. 2014 evidence-based guideline for the management of high blood pressure in adults: report from the panel members appointed to the Eighth Joint National Committee (JNC 8). JAMA. 2014;311(5):507-520. 
22. Stone NJ, Robinson JG, Lichtenstein AH, et al. 2013 ACC/AHA guideline on the treatment of blood cholesterol to reduce atherosclerotic cardiovascular risk in adults: a report of the American College of Cardiology/American Heart Association Task Force on Practice Guidelines. Circulation. 2014;129(25 Suppl 2):S1-S45.

23. Heart Protection Study Collaborative Group. MRC/BHF Heart Protection Study of cholesterol lowering with simvastatin in 20,536 high-risk individuals: a randomised placebo-controlled trial. Lancet. 2002;360(9326):7-22.

24. Antithrombotic Trialists' Collaboration. Collaborative meta-analysis of randomised trials of antiplatelet therapy for prevention of death, myocardial infarction, and stroke in high risk patients. BMJ. 2002;324(7329):71-86. Erratum in: BMJ 2002;324(7330):141.

25. CAPRIE Steering Committee. A randomised, blinded, trial of clopidogrel versus aspirin in patients at risk of ischaemic events (CAPRIE). CAPRIE Steering Committee. Lancet. 1996;348(9038): 1329-1339.

26. Fokkenrood HJ, Bendermacher BL, Lauret GJ, Willigendael EM, Prins MH, Teijink JA. Supervised exercise therapy versus non-supervised exercise therapy for intermittent claudication. Cochrane Database Syst Rev. 2013;8:CD005263.

27. Gardner AW, Poehlman ET. Exercise rehabilitation programs for the treatment of claudication pain. A meta-analysis. JAMA. 1995;274(12) 975-980.

28. Meier GH. Current literature for evidence-based infrainguinal endovascular treatment. Semin Vasc Surg. 2008;21(4):210-216.

29. Goodney PP, Beck AW, Nagle J, Welch HG, Zwolak RM. National trends in lower extremity bypass surgery, endovascular interventions, and major amputations. J Vasc Surg. 2009;50(1):54-60.

30. Joels CS, York JW, Kalbaugh CA, Cull DL, Langan EM 3rd, Taylor SM Surgical implications of early failed endovascular intervention of the superficial femoral artery. J Vasc Surg. 2008;47(3):562-565.

31. Ryer EJ, Trocciola SM, DeRubertis R, et al. Analysis of outcomes following failed endovascular treatment of chronic limb ischemia Ann Vasc Surg. 2006;20(4):440-446.

32. Adam DJ, Beard JD, Cleveland T, et al; BASIL trial participants. Bypass versus angioplasty in severe ischaemia of the leg (BASIL): multicentre randomised controlled trial. Lancet. 2005;366(9501):1925-1934.

33. Bradbury AW, Adam DJ, Bell J, et al; BASIL trial participants. Bypass versus angioplasty in severe ischaemia of the leg (BASIL) trial: analysis of amputation free and overall survival by treatment received. $J$ Vasc Surg. 2010;51(Suppl 5):18S-31S.

34. Pentecost MJ, Criqui MH, Dorros G, et al. Guidelines for peripheral percutaneous transluminal angioplasty of the abdominal aorta and lower extremity vessels. A statement for health professionals from a special writing group of the Councils on Cardiovascular Radiology, Arteriosclerosis, Cardio-Thoracic and Vascular Surgery, Clinical Cardiology, and Epidemiology and Prevention, the American Heart Association. Circulation. 1994;89(1):511-531.

35. Taylor SM, York JW, Cull DL, Kalbaugh CA, Cass AL, Langan EM Clinical success using patient-oriented outcome measures after lower extremity bypass and endovascular intervention for ischemic tissue loss. J Vasc Surg. 2009;50(3):534-541; discussion 541.

36. Conte MS. Bypass versus angioplasty in severe ischaemia of the leg (BASIL) and the (hoped for) dawn of evidence-based treatment for advanced limb ischemia. J Vasc Surg. 2010;51(Suppl 5):69S-75S

37. Jens S, Conijn AP, Koelemay MJ, Bipat S, Reekers JA. Randomized trials for endovascular treatment of infrainguinal arterial disease: systemic review and meta-analysis (Part 1: Above the knee). Eur JVasc Endovasc Surg. 2014;47(5):524-535.

38. Simpson EL, Michaels JA, Thomas SM, Cantrell AJ. Systematic review and meta-analysis of additional technologies to enhance angioplasty for infrainguinal peripheral arterial occlusive disease. Br J Surg. 2013;100(9):1128-1137.

39. Schillinger M, Sabeti S, Dick P, et al. Sustained benefit at 2 years of primary femoropopliteal stenting compared with balloon angioplasty with optional stenting. Circulation. 2007;115(21):2745-2749.
40. Laird JR, Ketzen BT, Scheinert D, et al; RESILIENT Investigators. Nitinol stent implantation versus balloon angioplasty for lesions in the superficial femoral artery and proximal popliteal artery: twelve-month results from the RESILIENT randomized trial. Circ Cardiovasc Interv. 2010;3(3):267-276.

41. Schmieder GC, Richardson AI, Scott EC, Stokes GK, Meier GH, Panneton JM. Selective stenting in subintimal angioplasty: analysis of primary stent outcomes. JVasc Surg. 2008;48(5):1175-1180; discussion 1180-1181.

42. Bachoo P, Thorpe PA, Maxwell H, Welch K. Endovascular stents for intermittent claudication. Cochrane Database Syst Rev. 2010;1: CD003228.

43. Mwipatayi BP, Hockings A, Hofmann M, Garbowski M, Sieunarine K. Balloon angioplasty compared with stenting for treatment of femoropopliteal occlusive disease: a meta-analysis. J Vasc Surg. 2008;47(2): 461-469.

44. Geraghty PJ, Mewissen MW, Jaff MR, Ansel GM; VIBRANT Investigators. Three-year results of the VIBRANT trial of VIABAHN endoprosthesis versus bare nitinol stent implantation for complex superficial femoral artery occlusive disease. J Vasc Surg. 2013;58(2):386-395. e4.

45. Lammer J, Zeller T, Hausegger KA, et al. Heparin-bonded covered stents versus bare-metal stents for complex femoropopliteal artery lesions: the randomized VIASTAR trial (Viabahn endoprosthesis with PROPATEN bioactive surface [VIA] versus bare nitinol stent in the treatment of long lesions in superficial femoral artery occlusive disease). J Am Coll Cardiol. 2013;62(15):1320-1327.

46. McQuade K, Gable D, Pearl G, Theune B, Black S. Four-year randomized prospective comparison of percutaneous ePTFE/nitinol selfexpanding stent graft versus prosthetic femoral-popliteal bypass in the treatment of superficial femoral artery occlusive disease. J Vasc Surg. 2010;52(3):584-590; discussion 590-591, 591. e1-591.e7.

47. Siablis D, Karnabatidis D, Katsanos K, et al. Sirolimus-eluting versus bare stents after suboptimal infrapopliteal angioplasty for critical limb ischemia: enduring 1-year angiographic and clinical benefit. JEndovasc Ther. 2007;14(2):241-250.

48. Giles KA, Pomposelli FB, Spence TL, et al. Infrapopliteal angioplasty for critical limb ischemia: relation of TransAtlantic InterSociety Consensus class to outcome in 176 limbs. J Vasc Surg. 2008;48(1):128-136.

49. Conrad MF, Kang J, Cambria RP, et al. Infrapopliteal balloon angioplasty for the treatment of chronic occlusive disease. J Vasc Surg. 2009;50(4):799-805.e4.

50. Conte MS, Bandyk DF, Clowes AW, et al; PREVENT III Investigators. Results of PREVENT III: a multicenter, randomized trial of edifoligide for the prevention of vein graft failure in lower extremity bypass surgery. J Vasc Surg. 2006;43(4):742-751; discussion 751.

51. Conte MS, Geraghty PJ, Bradbury AW, et al. Suggested objective performance goals and clinical trial design for evaluating catheterbased treatment of critical limb ischemia. J Vasc Surg. 2009;50(6): 1462-1473. e1.

52. Mills JL Sr. Infrainguinal disease: Surgical treatment. In: Cronenwett JL, Johnston KW, editors. Rutherford's Vascular Surgery. 8th ed. Philadelphia, PA: Elsevier Saunders; 2014:1758-1781.

53. Klinkert P, Schepers A, Burger DH, van Bockel JH, Breslau PJ. Vein versus polytetrafluoroethylene in above-knee femoropopliteal bypass grafting: five-year results of a randomized controlled trial. J Vasc Surg. 2003;37(1):149-155.

54. Johnson WC, Lee KK. A comparative evaluation of polytetrafluoroethylene, umbilical vein, and saphenous vein bypass grafts for femoral-popliteal above-knee revascularization: a prospective randomized Department of Veterans Affairs cooperative study. J Vasc Surg. 2000;32(2):268-277.

55. Gentile AT, Lee RW, Moneta GL, Taylor LM, Edwards JM, Porter JM. Results of bypass to the popliteal and tibial arteries with alternative sources of autogenous vein. J Vasc Surg. 1996;23(2):272-279; discussion 279-280.

56. Schanzer A, Hevelone N, Owens CD, et al. Technical factors affecting autogenous vein graft failure: observations from a large multicenter trial. J Vasc Surg. 2007;46(6):1180-1190; discussion 1190. 
57. Hölzenbein TJ, Pomposelli FB, Miller A, et al. The upper arm basiliccephalic loop for distal bypass grafting: technical considerations and follow-up. J Vasc Surg. 1995;21(4):586-592; discussion 592-594.

58. LoGerfo FW, Paniszyn CW, Menzoian J. A new arm vein graft for distal bypass. J Vasc Surg. 1987;5(6):889-891.

59. Post S, Kraus T, Müller-Reinartz U, et al. Dacron vs. polytetrafluoroethylene grafts for femoropopliteal bypass: a prospective randomised multicentre trial. Eur J Vasc Endovasc Surg. 2001;22(3):226-231.

60. Robinson BI, Fletcher JP, Tomlinson P, et al. A prospective randomized multicentre comparison of expanded polytetrafluoroethylene and gelatin-sealed knitted Dacron grafts for femoropopliteal bypass. Cardiovasc Surg. 1999;7(2):214-218.

61. Devine C, McCollum C; North West Femoro-Popliteal Trial Participants. Heparin-bonded Dacron or polytetrafluorethylene for femoropopliteal bypass: five-year results of a prospective randomized multicenter clinical trial. J Vasc Surg. 2004;40(5):924-931.

62. Devine C, Hons B, McCollum C. Heparin-bonded Dacron or polytetrafluoroethylene for femoropopliteal bypass grafting: a multicenter trial. J Vasc Surg. 2001;33(3):533-539.

63. Aalders GJ, van Vroonhoven TJ. Polytetrafluoroethylene versus human umbilical vein in above-knee femoropopliteal bypass: six-year results of a randomized clinical trial. JVasc Surg. 1992;16(6):816-823; discussion 823-824.

64. Scharn DM, Dirven M, Barendregt WB, Boll AP, Roelofs D, van der Vliet JA. Human umbilical vein versus heparin-bonded polyester for femoro-popliteal bypass: 5-year results of a prospective randomized multicentre trial. Eur J Vasc Endovasc Surg. 2008;35(1):61-67.

65. Eickhoff JH, Broomé A, Ericsson BF, et al. Four years' results of a prospective, randomized clinical trial comparing polytetrafluoroethylene and modified human umbilical vein for below-knee femoropopliteal bypass. J Vasc Surg. 1987;6(5):506-511.

66. Green RM, Abbott WM, Matsumoto T, et al. Prosthetic above-knee femoropopliteal bypass grafting: five-year results of a randomized trial. J Vasc Surg. 2000;31(3):417-425.

67. Albers M, Battistella VM, Romiti M, Rodrigues AA, Pereira CA. Meta-analysis of polytetrafluoroethylene bypass grafts to infrapopliteal arteries. J Vasc Surg. 2003;37(6):1263-1269.
68. Griffiths GD, Nagy J, Black D, Stonebridge PA. Randomized clinical trial of distal anastomotic interposition vein cuff in infrainguinal polytetrafluoroethylene bypass grafting. Br J Surg. 2004;91(5): 560-562.

69. Miller JH, Foreman RK, Ferguson L, Faris I. Interposition vein cuff for anastomosis of prosthesis to small artery. Aust $N$ Z J Surg. 1984;54(3):283-285.

70. Ducasse E, Chevalier J, Chevier E, et al. Patency and limb salvage after distal prosthetic bypass associated with vein cuff and arteriovenous fistula. Eur J Vasc Endovasc Surg. 2004;27(4):417-422.

71. Farber A, Major K, Wagner WH, et al. Cryopreserved saphenous vein allografts in infrainguinal revascularization: analysis of 240 grafts. J Vasc Surg. 2003;38(1):15-21.

72. Randon C, Jacobs B, De Ryck F, Beele H, Vermassen F. Fifteen years of infrapopliteal arterial reconstructions with cryopreserved venous allografts for limb salvage. J Vasc Surg. 2010;51(4):869-877.

73. Tan TW, Rybin D, Kalish JA, et al; Vascular Study Group of New England. Routine use of completion imaging after infrainguinal bypass is not associated with higher bypass graft patency. J Vasc Surg. 2014;60(3):678-685. e2.

74. Lundell A, Lindblad B, Bergqvist D, Hansen F. Femoropopliteal-crural graft patency is improved by an intensive surveillance program: a prospective randomized study. J Vasc Surg. 1995;21(1):26-33; discussion 33-34.

75. Visser K, Idu MM, Buth J, Engel GL, Hunink MG. Duplex scan surveillance during the first year after infrainguinal autologous vein bypass grafting surgery: costs and clinical outcomes compared with other surveillance programs. J Vasc Surg. 2001;33(1):123-130.

76. Tangelder MJ, Algra A, Lawson JA, Hennekes S, Eikelboom BC. Optimal oral anticoagulant intensity to prevent secondary ischemic and hemorrhagic events in patients after infrainguinal bypass graft surgery. Dutch BOA Study Group. J Vasc Surg. 2001;33(3):522-527.

77. Geraghty AJ, Welch K. Antithrombotic agents for preventing thrombosis after infrainguinal arterial bypass surgery. Cochrane Database Syst Rev. 2011;6:CD000536.
Vascular Health and Risk Management

\section{Publish your work in this journal}

Vascular Health and Risk Management is an international, peerreviewed journal of therapeutics and risk management, focusing on concise rapid reporting of clinical studies on the processes involved in the maintenance of vascular health; the monitoring, prevention and treatment of vascular disease and its sequelae; and the involvement of

\section{Dovepress}

metabolic disorders, particularly diabetes. This journal is indexed on PubMed Central and MedLine. The manuscript management system is completely online and includes a very quick and fair peer-review system, which is all easy to use. Visit http://www.dovepress.com/ testimonials.php to read real quotes from published authors. 